\title{
Capillary Hemangioma in Maxillary Anterior Region: A Case Report
}

\author{
${ }^{1}$ V Satish, ${ }^{2}$ Manohar Bhat, ${ }^{3}$ Prabhadevi C Maganur, ${ }^{4}$ Parth Shah, ${ }^{5}$ Vijay Biradar
}

\begin{abstract}
Hemangiomas are relatively common benign proliferative lesion of vascular tissue origin. They are often present at birth and may become more apparent throughout life. They are seen on facial skin, tongue, lips, buccal mucosa and palate as well as muscles. Hemangiomas occur more common in females than males. This case report presents a case of capillary hemangioma in maxillary anterior region in a 10 -year-old boy.
\end{abstract}

Keywords: Hemangioma, Capillary hemangioma, Benign tumor, Vascular lesions.

How to cite this article: Satish V, Bhat M, Maganur PC, Shah $P$, Biradar V. Capillary Hemangioma in Maxillary Anterior Region: A Case Report. Int J Clin Pediatr Dent 2014;7(2):144-147.

Source of support: Nil

Conflict of interest: None declared

\section{INTRODUCTION}

Hemangioma is relatively common benign proliferative lesion of vascular tissue origin, which may be present either at birth or may arise during early childhood. ${ }^{1}$ Hemangiomas are considered to be benign tumors of infancy that are characterized by a raid growth phase with endothelial cell proliferation followed by gradual involution. ${ }^{2}$ The proliferation of the cells does not undergo malignant transformation. ${ }^{3,4}$ Most hemangiomas cannot be recognized at birth, but arise subsequently during the 8 weeks of life, but older age individuals may also be occasionally be affected. Incidence of occurrence is seen in female than male. ${ }^{2}$ Eighty percent of hemangioma occurs as single lesion, but $20 \%$ of affected patients will have multiple tumors. ${ }^{2}$ They appear as pale macules with thread-like telangiectasia over the skin and mucous membrane. ${ }^{1}$ They are soft and painless. They are described clinically as a soft tissue mass, smooth or lobulated sessile or pedunculated with variable size. They may be smooth or

\footnotetext{
${ }^{1}$ Professor, ${ }^{2}$ Professor and Head, ${ }^{3,5}$ Reader

${ }^{4}$ Ex-Postgraduate Student

${ }^{1,2-4}$ Department of Pediatric Dentistry, Jaipur Dental College Jaipur, Rajasthan, India

${ }^{5}$ Department of Oral Pathology, Jaipur Dental College, Jaipur Rajasthan, India
}

Corresponding Author: $V$ Satish, Professor, Department of Pediatric Dentistry, Jaipur Dental College, Jaipur, Rajasthan India, e-mail: drvsatish@rediffmail.com irregular bulbous in outline. ${ }^{5}$ This article describes the case of a 10-year-old boy reported with a growth arising from attached gingiva in the maxillary anterior region.

\section{CASE REPORT}

A male patient aged 10 years reported with a painless swelling in upper left anterior region from past 3 months. Soft tissue overgrowth was seen in relation to 22 and 63 involving attached gingiva (Fig. 1). History revealed excision of the lesion 3 months back in the same region. After 1 month of excision, the lesion reoccurred. Patient does not give any history of pain in that region.

\section{GENERAL EXAMINATION}

Extraoral examination including the lymph nodes was insignificant. Intraoral examination revealed a localized gingival growth which was pinkish white in color, arising from the attached gingiva of deciduous maxillary canine and maxillary 1st molar but was not interfering the occlusion. Tooth no. 64 was having proximal caries. There was grade II mobility with respect to 63 and 64 . The oral hygiene was reasonably good.

A provisional diagnosis of hemangioma was made due to its clinical appearance and its growth. Preoperative hematological test revealed all findings to be normal. The lesion was excised under local anesthesia (Figs 2 and 3). Postsurgical instructions were given. The excised growth was sent to histopathological examination. Satisfactory uneventful healing occurred after 1 month (Fig. 4). Tooth no. 63 and 64 were extracted and Nance palatal arch space maintainer was delivered (Fig. 5). Patient is under follow-up to monitor the reoccurrence (Fig. 6).

\section{Description of the Excised Lesion}

Single mass of tissue measuring $0.8 \times 0.5 \times 0.1 \mathrm{~cm}$, pinkish white in color, firm in consistency, roughed surface and irregular in shape.

\section{MICROSCOPIC FEATURES}

The H\&E stained soft tissue section shows lobulated cellular growth which is separated by fibrillar connective tissue. These lobules contain plump proliferating endothelial cells, 


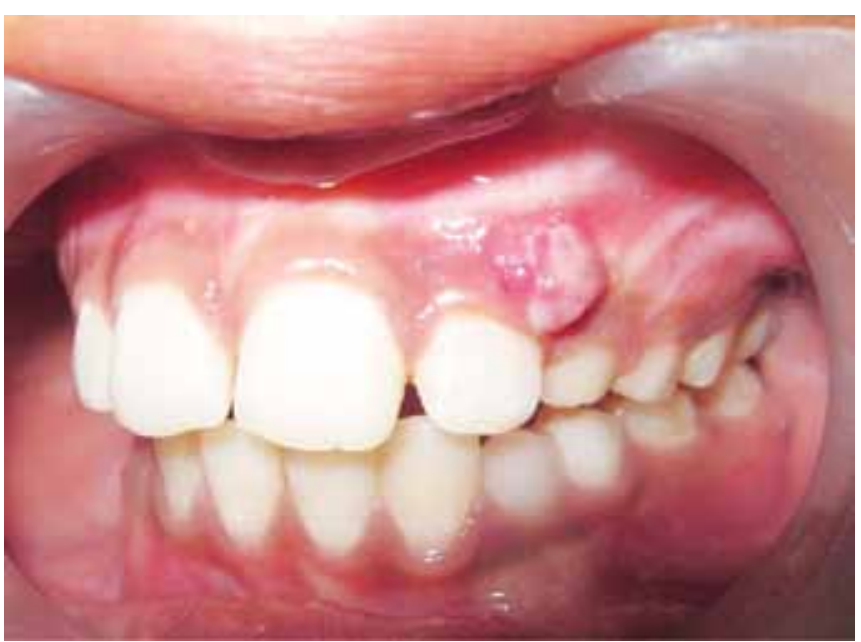

Fig. 1: Preoperative image showing a gingival soft tissue overgrowth irt 22 and 63

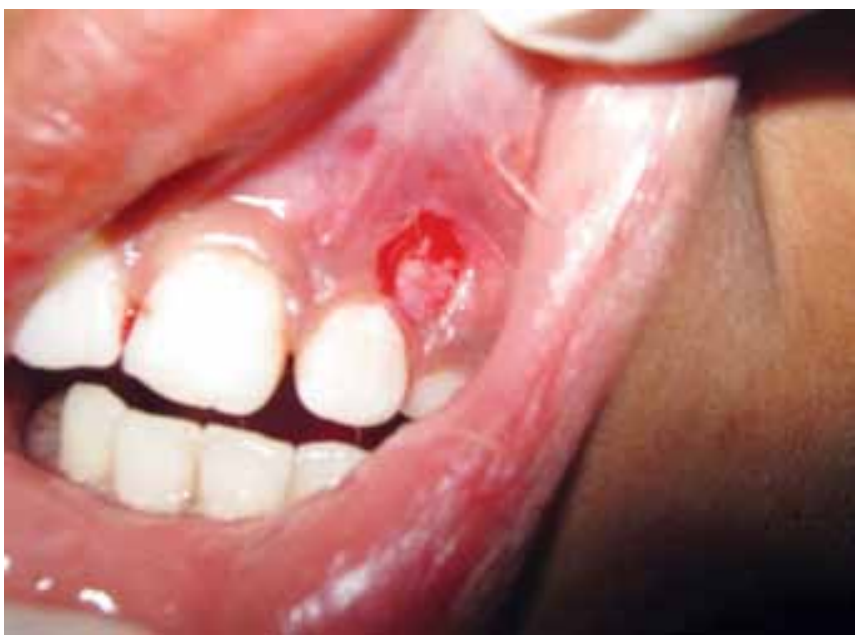

Fig. 3: Complete excision of the lesion

combination of numerous well and poorly canalized blood vessels which are lined by endothelial cells.

The overlying epithelium is parakeratotic stratified squamous type. The intervening connective tissue stroma is fibrillar composed of loose bundles of collagen fibers. It is sparsely infiltrated with chronic inflammatory cells predominantly lymphocytes and plasma cells (Figs 7 to 9).

\section{DIAGNOSIS}

On the basis of clinical and histopathological findings capillary hemangioma was made.

\section{DISCUSSION}

The word hemangioma comes from Greek word, hema'blood', angeio - 'vessel', oma - 'tumor'. This terminology has been widely used in medical and dental literature. In $80 \%$ of cases, hemangiomas occur as single lesions. More over, capillary hemangiomas have a 3:1 female to male ratio and occur more frequently among Caucasians than other racial groups. ${ }^{6}$ Although the exact etiology is unknown,

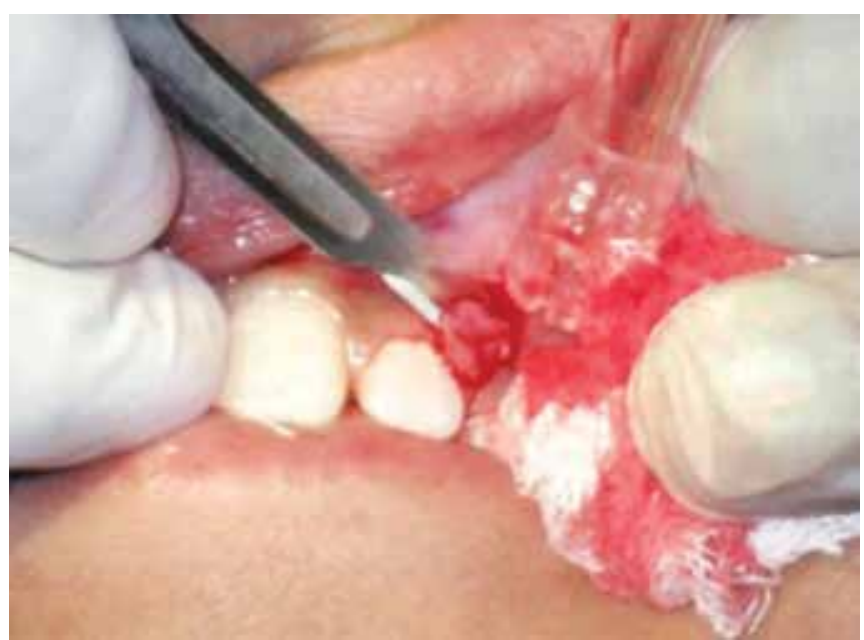

Fig. 2: Incision with no. 15 BP blade

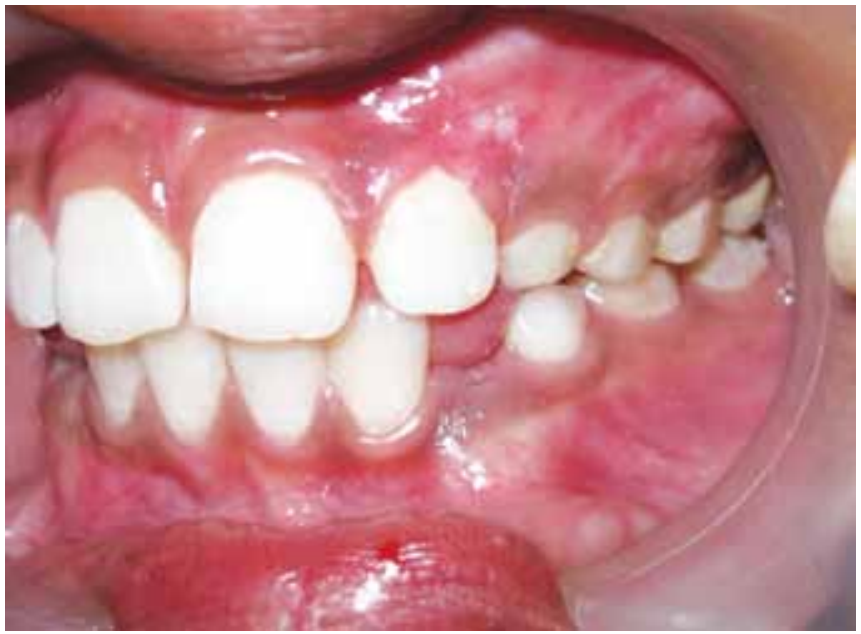

Fig. 4: Postoperative image - after 1 month

some authors believe that this lesion is not true lesion, but rather a developmental anomaly or hamartoma. ${ }^{7}$

Vascular lesions are the most common congenital abnormality. ${ }^{8,9}$ Vascular lesions are generally divided into two categories: Hemangioma and vascular malformations. Hemangiomas are benign vascular anomalies characterized by benign proliferation of blood vessels. There are no welldefined criteria for the diagnosis and treatment of oral capillary hemangioma. ${ }^{10}$ The term hemangioma has been commonly used to describe a large number of vasoformative tumors. They are benign, vascular tumor that can lead to disfigurement or life-threatening consequences. Hemangiomas are usually classified into capillary, cavernous and mixed hemangioma.

\begin{tabular}{ll}
\hline Capillary hemangioma & Cavernous hemangioma \\
\hline $\begin{array}{l}\text { Numerous proliferating small } \\
\text { thin-walled blood filled vessels }\end{array}$ & $\begin{array}{l}\text { Deep irregular, dermal tangles } \\
\text { of large thin-walled vessels or } \\
\text { sinusoids }\end{array}$ \\
$\begin{array}{l}\text { Surrounded by discontinuous } \\
\text { layer of pericytes and reticular } \\
\text { fibers }\end{array}$ & $\begin{array}{l}\text { Surrounded by discontinuous } \\
\text { layer of endothelial cells }\end{array}$ \\
$\begin{array}{l}\text { Single layer of flattened or } \\
\text { plump endothelial cells }\end{array}$ & $\begin{array}{l}\text { Separated by scanty } \\
\text { connective tissue }\end{array}$ \\
\hline
\end{tabular}




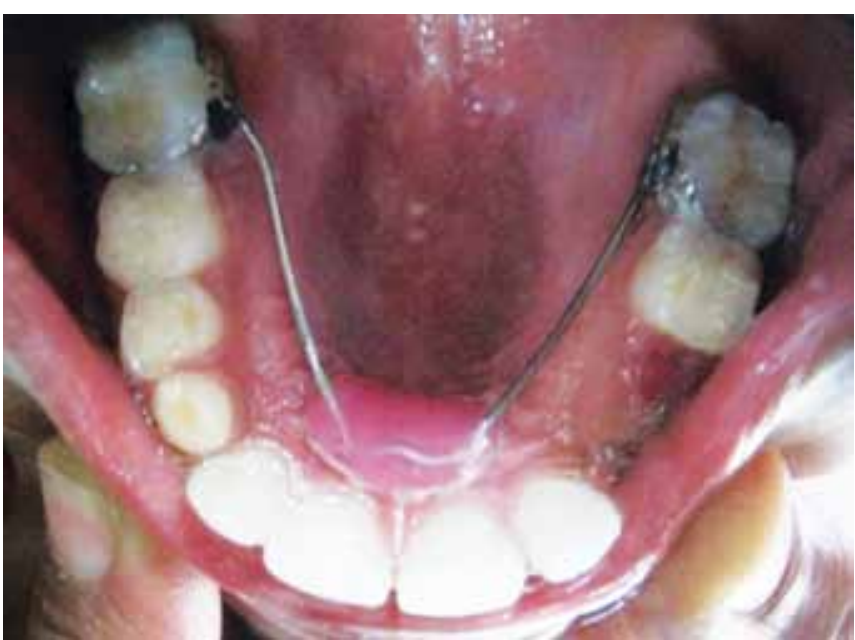

Fig. 5: Extraction of 63 and 64 followed by Nance palatal arch space maintainer

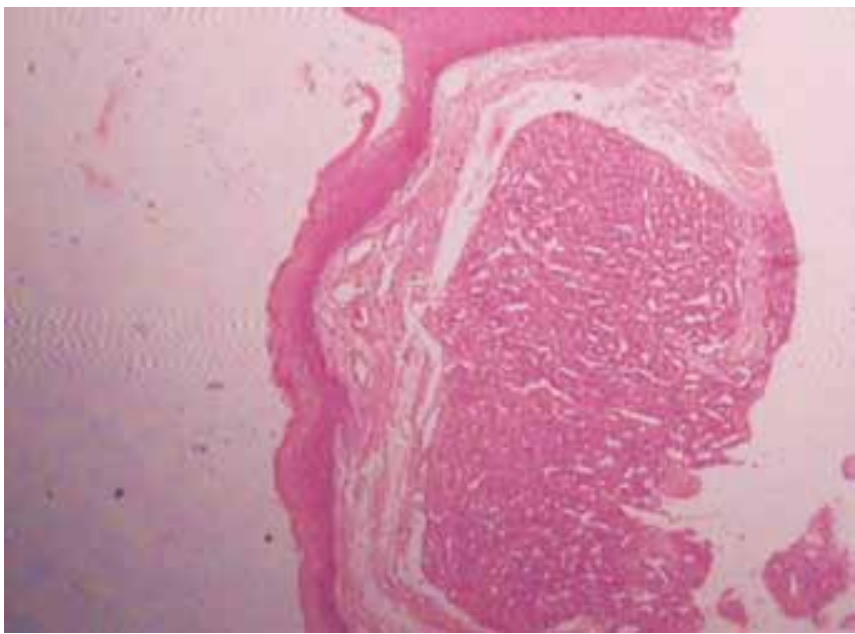

Fig. 7: Complete area of epithelium and connective tissue filled with capillaries $(4 \times$ view $)$

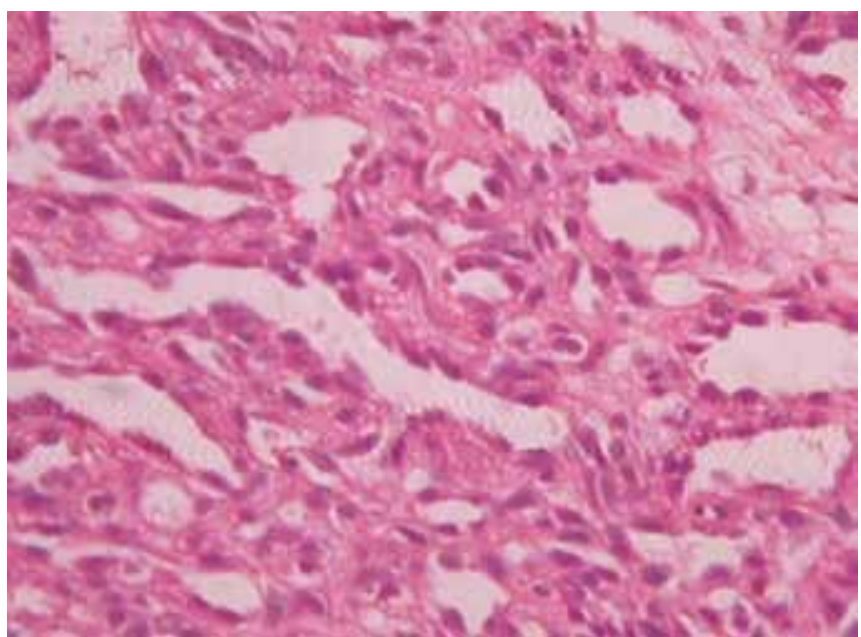

Fig. 9: Small to enlarged capillaries lined by endothelial cells $(40 \times$ view)

The diagnosis of hemangioma is straightforward from the history and clinical examination. Hemangiomas usually appear within a few weeks after birth and have a growth rate that exceeds the growth rate of children. ${ }^{11,12}$ Hemangiomas generally do not affect adjacent bones and they can be shallow

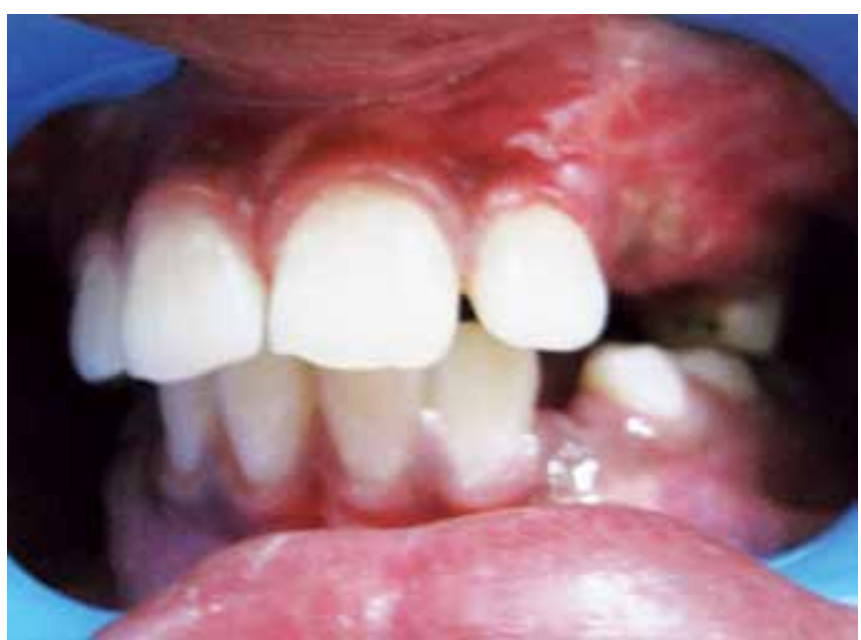

Fig. 6: Follow-up after 2 months

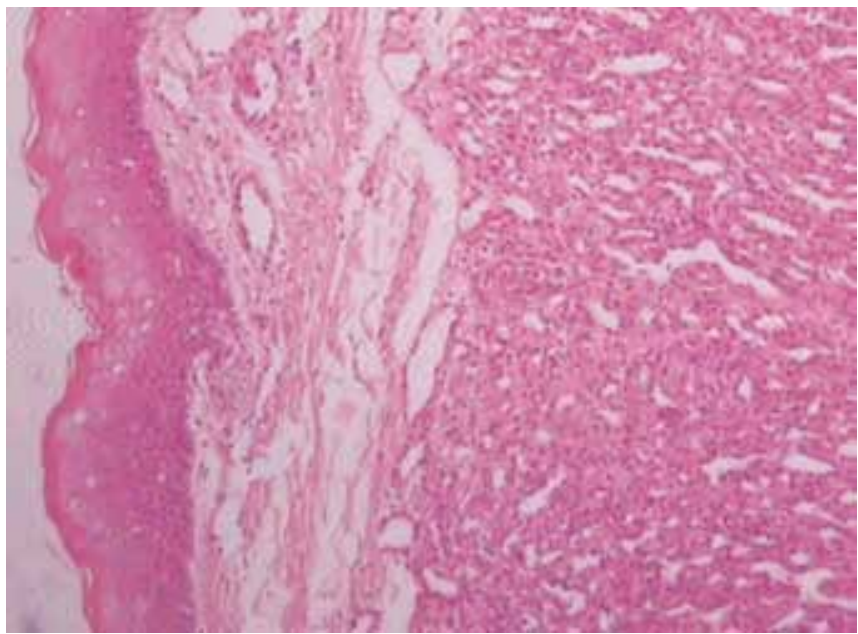

Fig. 8: Epithelium and collagenous stroma showing capillaries (10x view)

or deep. Sometimes, they can even involve all layers of the skin and offend the muscles. ${ }^{13}$

At the cellular level, hemangiomas are characterized by increased birth and death rate of endothelial cells and proliferation of mastocytes during the postnatal proliferative phase in the lesion. Derived from young proliferating hemangiomas, capillary endothelium is easily grown in cell culture mediums and forms tubes. In accumulated hemangiomas, the number of mastocytes decreases and becomes equal to natural tissues. Hence, a normal hemangioma is an endothelial tumor with a very complex life cycle of cell proliferation and natural regression. Vascular malformations are the second major group of vascular lesions. In fact, they are an abnormal morphogenesis of blood or lymphatic vessels. Vascular malformations are present at birth. However, their clinical manifestations are not obvious sometimes until late infancy or even childhood. ${ }^{14}$

The literature suggests capillary hemangioma is observed as a relatively rare and uncommon pathologic entity in the oral cavity, but is a common soft tissue tumor of head and 
neck. Occurrence of capillary hemangioma with its primary location on gingiva seems extremely rare. The most frequent site of occurrence of intraoral hemangiomas are lips, tongue, buccal mucosa and palate. ${ }^{1,15}$ It is very rare to find hemangioma on attached gingiva. The same observation was seen by Mishra MB et al in a 30-year-old female patient. ${ }^{16}$ Our case describes an capillary hemangioma in a male child occurring on the attached gingiva of maxillary anterior region. Clinical findings in corelation with histopathologic findings confirm our case as capillary hemangioma.

Regarding treatment, hemangiomas require no intervention. At an early age, spontaneous regression takes place. Only 10 to $20 \%$ require treatment, because of their size, location in their behavior. Different treatment procedures used in treating hemangiomas include microembolization, radiation, cryotherapy, sclerosing agents, surgical excision and recently Erbium lasers have been used. In the present case, the treatment compromised of complete surgical excision of the lesion. In the case discussed here, the patient is undergoing follow-up and no sign of recurrence has been seen.

\section{CONCLUSION}

Any tumor, whether benign or malignant to be treated, requires early detection and diagnosis to avoid any complications at a later date. Capillary hemangiomas may be small but may cause problems in esthetics, mastication, phonetics and self-confidence in the human. There are many treatment options for hemangiomas where in surgical excision is one of the gold standard treatment regime.

\section{REFERENCES}

1. Purkait SK. Essentials of oral pathology. 3rd ed. Jaypee Brothers Medical Publishers Pvt Ltd; 2011. p. 120-121.
2. Neville, Damm, Allen CM, Bouquot JE. Oral and maxillofacial pathology. 2nd ed. India: Elsevier Publication; 2002. p. 467-471.

3. Enzinger FM, Weiss SW. Soft tissue tumours. 3rd ed. St. Louis: Mosby; 1995. p. 581-586.

4. Silverman RA. Haemangiomas and vascular formulations. Pediatr Clin North Am 1991;38:811-834.

5. Carranza FA. Glickman's clinical periodontolgy. 1st ed. Philadelphia: WB Saunders Co London; 1990. p. 335-351.

6. Braun IF, Levy S, Hoffman J. The use of transarterial microembolization in the management of haemangiomas of the perioral region. J Oral Maxillofac Surg 1985;43:239-248.

7. Shafer WG, Hire MK, Levy BM. A textbook of oral pathology. 4th ed. Philadelphia: WB Saunders Co; 1983. p. 154-157.

8. Werner JA, Dunne AA, Folz, Rochels R, Bien S, Ramaswamy A, et al. Current concepts in the classification, diagnosis and treatment of haemangiomas and vascular malformations of the head and neck. Eur Arch Otorhinolaryngol 2001;258:141-149.

9. Garzon MC, Enjolras O, Frieden IJ. Vascular tumours and vascular malformations: evidence for an association. J Am Acad Dermatol 2000;42:275-279.

10. da Silva WB, Riberio AL, de Menezes SA, de Jesus Viana PInherio J, de Melo Alves-Junior S. Oral capillary haemangioma: a clinical protocol of diagnosis and treatment in adults. Oral Maxillofac Surg 2013 Nov 22 (PMID: 24263242).

11. Low DW. Haemangiomas and vascular malformations. Semin Pediatr Surg 1994;3:40-61.

12. Waner M1, Suen JY. Management of congenital vascular lesions of the head neck. Oncology (Williston Park) 1995;9:989-994.

13. Bobyd JB, Mulliken JB, Kaban LB, Upton J. 3rd, Murray JE. Skeletal changes associated with vascular malformations. Plast Reconstr Surg 1984;74:789-797.

14. Mulliken JB, Glowacki J. Haemangioma and vascular malformations in infants and children: a classification based on endothelial characteristics. Plast Reconstr Surg 1982;63:412-422.

15. Mishra MB, Bishen KA, Yadav A. Capillary hemangioma: an occlusal growth of attached gingiva. J Indian Soc Periodontol 2012 Oct-Dec;16(4):592-596.

16. Bharti V, Singh J. Capillary haemangioma of palatal mucosa. J Indian Soc Periodontol 2012 Jul-Sep;16(3):475-478. 